\title{
Synthesis and Characterization of
}

\section{Poly(glyceryl glycerol) Block Copolymers}

\author{
Frederik Wurm, Jörg Nieberle and Holger Frey* \\ Institute of Organic Chemistry, Organic and Macromolecular Chemistry, Duesbergweg 10-14, \\ Johannes Gutenberg-University Mainz, D-55099 Mainz, Germany. \\ Contact address: hfrey@uni-mainz.de
}

\section{Experimental:}

Instrumentation: ${ }^{1} \mathrm{H}-\mathrm{NMR}$ spectra were recorded at $300 \mathrm{MHz}$ on a Bruker $\mathrm{AC}$ and were referenced internally to residual proton signals of the deuterated solvent.

SEC measurements in DMF (containing $1 \mathrm{~g} / \mathrm{L}$ of lithium bromide as an additive) an Agilent 1100 Series was used as an integrated instrument including a PSS Gral column $\left(10^{4} / 10^{4} / 10^{2} \AA\right.$ porosity), a UV (275 nm) and a RI detector. Calibration was done using poly(styrene) or poly(ethylene oxide) standards provided by Polymer Standards Service.

DSC measurements were carried out on a Perkin-Elmer 7 series thermal analysis system and a Perkin Elmer Thermal Analysis Controler TAC 7/DX in the temperature range from 100 to $100^{\circ} \mathrm{C}$ at heating rates of $10 \mathrm{~K} \cdot \mathrm{min}^{-1}$ under nitrogen.

Reagents: Diglyme (99\% Acros) and methoxy ethanol (99.5\% Acros) for polymerizations were purified by distillation from $\mathrm{CaH}_{2}$ just prior to use. Ethylene oxide 99.5\% (Aldrich) was used without further purification. Polyethylene oxide monomethyl ether was purchased from 
Fluka and used as received. Cesium hydroxide monohydrate was purchased from Acros and used as received. Deuterated chloroform- $\mathrm{d}_{1}$ and DMSO- $\mathrm{d}_{6}$ were purchased from Deutero $\mathrm{GmbH}$ and dried and stored over molecular sieves. Methanol, chloroform, and other solvents and reagents were purchased from Acros and used as received as not otherwise mentioned.

\section{General procedures:}

\section{Synthesis of (1):}

$13 \mathrm{~g}$ (99 mmol) Solketal was dissolved in $20 \mathrm{~mL}$ benzene, $20 \mathrm{~mL}$ of a $50 \% \mathrm{NaOH}$ and 3,22g (10 mmol) tetrabutyl ammonium bromide (TBAB) was added. The mixture was cooled to ca. $10^{\circ} \mathrm{C}$ and $18,35 \mathrm{~g}(200 \mathrm{mmol})$ epichlorohydrine was slowly added with a syringe. The reaction was vigorously stirred at room temperature for $48 \mathrm{~h}$, diluted with ether and washed three times with water, saturated $\mathrm{NaHCO}_{3}$ and $\mathrm{NaCl}$, and finally dried over $\mathrm{MgSO}_{4}$. Diethyl ether and excess of epichlorohydrine was removed in vacuo and the crude product was distilled in vacuo (b.p. $90^{\circ} \mathrm{C}$ at $10^{-2}$ mbar, yield $51 \%$. Purification via column chromatography (silica, diethyl ether: petroleum ether 5:3) results in higher yields (70-90\%). ${ }^{1} \mathrm{H}-\mathrm{NMR}(400 \mathrm{MHz}$, $\mathrm{CDCl}_{3}, \delta$ in ppm): $4.3(\mathrm{~m}, 1 \mathrm{H}, \mathrm{CH}$ acetal $), 4.07(\mathrm{~m}, 1 \mathrm{H}), 3.88-3.39(\mathrm{~m}, 6 \mathrm{H}), 3.17(\mathrm{~m}, 1 \mathrm{H})$, $2.81\left(\mathrm{t}, 1 \mathrm{H}, \mathrm{CH}_{2}\right.$ epoxide), 2.63 (q, $1 \mathrm{H}, \mathrm{CH}_{2}$ epoxide), $1.44\left(\mathrm{~s}, 3 \mathrm{H}, \mathrm{CH}_{3}\right), 1.38\left(\mathrm{~s}, 3 \mathrm{H}, \mathrm{CH}_{3}\right)$.

${ }^{13} \mathrm{C}-\mathrm{NMR}$ (97 MHz, $\mathrm{CDCl}_{3}, \delta$ in ppm): 109.4 (quart. $\mathrm{C}$ acetal), 74.6 (tert. $\mathrm{CH}$ acetal), 74.4$74.1\left(\mathrm{CH}_{2}\right), 66.6\left(\mathrm{CH}_{2}\right.$, acetal), $50.7(\mathrm{CH}$, epoxide $), 44.1\left(\mathrm{CH}_{2}\right.$ epoxide $), 26.7 \mathrm{CH}_{3}$, acetal $)$, $25.3\left(\mathrm{CH}_{3}\right.$, acetal). (compare SF 1 and SF 2 - assignment can be realized via 2D-NMR spectra SF 3/ SF 4).

\section{Polymerizations:}

a) Cesium hydroxide monohydrate was suspended in benzene in a Schlenk flask and a stoichiometric amount of methoxyethanol was added under argon with a syringe. Stirring at $60^{\circ} \mathrm{C}$ for 30 minutes and evacuation at $90^{\circ} \mathrm{C}$ for two hours gave the cesium alcoxide which 
was cooled to $0^{\circ} \mathrm{C}$. Then ethylene oxide was cryo transferred to a graduated ampoule, diluted with dioxane (ca. 50 weight $\%$ ) and added to the initiator via canula. The mixture was allowed to slowly warm up to room temperature and polymerization was performed for 2 days in vacuo. Then the flask was back filled with argon, the appropriate amount of freshly dried allyl glycidyl ether or solketyl glycidyl ether (1) was added with a syringe and temperature was rised to $80-90^{\circ} \mathrm{C}$ for $48-72 \mathrm{~h}$. The polymerization was terminated by addition of methanol and acidic ion exchange resin. Filtration and precipitation in cold diethyl ether resulted in the pure polymer. For polymers with greater amount of PAGE the polymer solution was dried in vacuo after filtration of the resin without precipitation.

b) For the polymerizations using commercially available MPEGs, the macroinitiator was dissolved in benzene (20 weight $\%$ ) and partially deprotonated (80-90\%) using cesium hydroxide, analogously to the previous procedure.

Deprotection of PSGE: The acetal protecting groups of PSGE were removed by the addition of $1 \mathrm{M}$ hydrochloric acid to a $20 \%$ solution of the polymer in ethanol and stirring for $30 \mathrm{~min}$. Afterwards an excess of potassium carbonate was added for neutralization. Filtration and precipitation in diethyl ether gave the pure block copolymer, that was dried in vacuo for 2 days at $80^{\circ} \mathrm{C}$.

Oxidation of PAGE: The allyl groups were oxidized using catalytical amount of $\mathrm{OsO}_{4}$ in combination with NMO. A typical reaction is described here: $1 \mathrm{~g}$ polymer is dissolved in a 5:1 mixture of acetone/ $\mathrm{t}-\mathrm{BuOH}$ to give a 20 weight $\%$ solution. $1,2 \mathrm{eq} /$ allyl group is added to the mixture and a few drops $(20-100 \mu \mathrm{L})$ of a $4 \%$ solution of $\mathrm{OsO}_{4}$ in water are added. The reaction is stirred for 24 hours at room temperature, filtrated through celite, concentrated in vacuo and precipitated three times into cold diethyl ether to give a slightly brown polymer. Final dialysis against methanol for two days with continuous solvent exchange only slightly brightened the material.

\section{Additional spectra:}




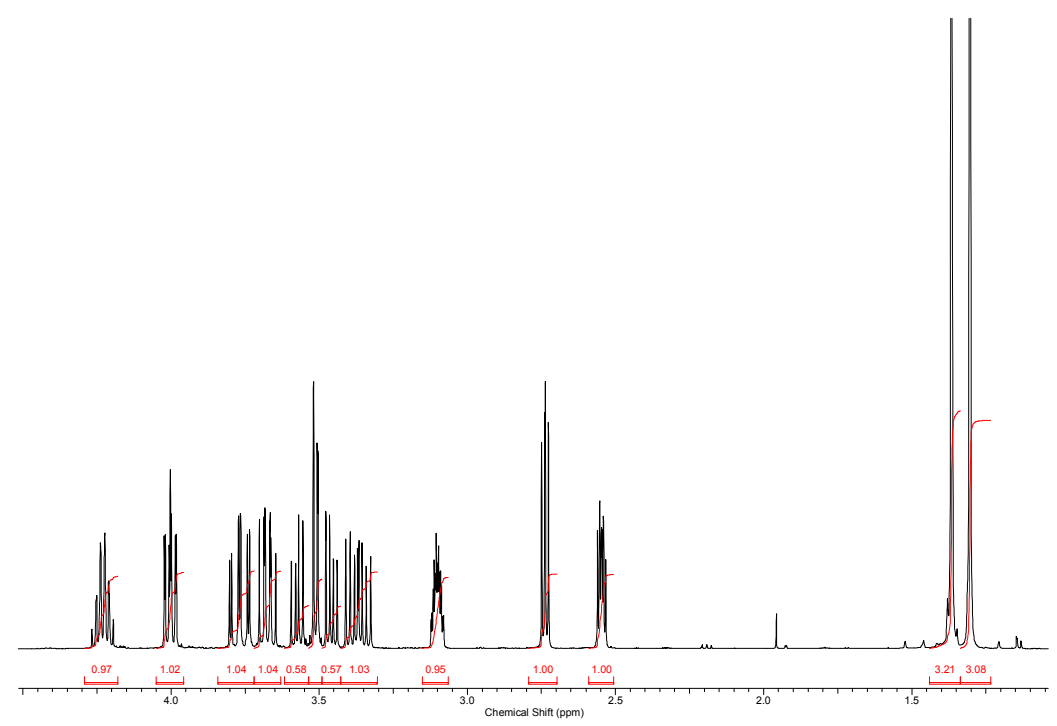

SF 1. ${ }^{1} \mathrm{H}-\mathrm{NMR}$ spectrum of $\mathbf{1}$ in $\mathrm{CDCl}_{3}$.

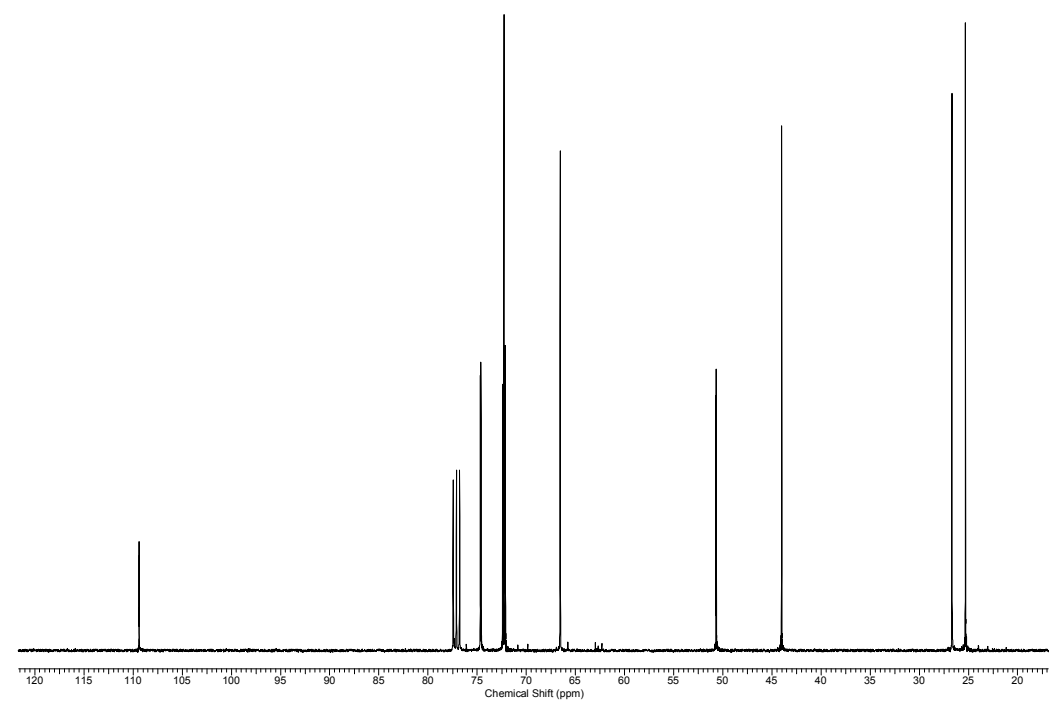

SF 2. ${ }^{13} \mathrm{C}$-NMR spectrum of $\mathbf{1}$ in $\mathrm{CDCl}_{3}$. 


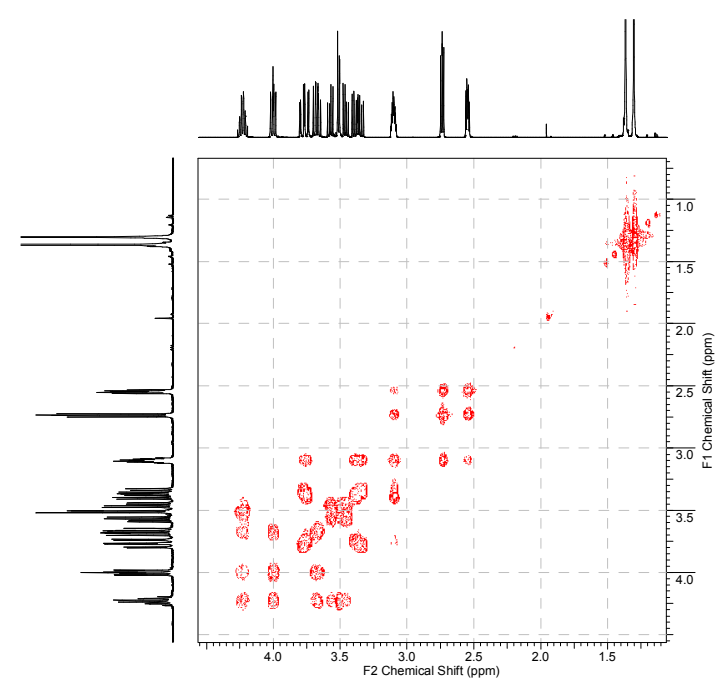

SF 3. $2 \mathrm{D}-\mathrm{COSY}-\mathrm{NMR}$ in $\mathrm{CDCl}_{3}$ of $\mathbf{1}$.

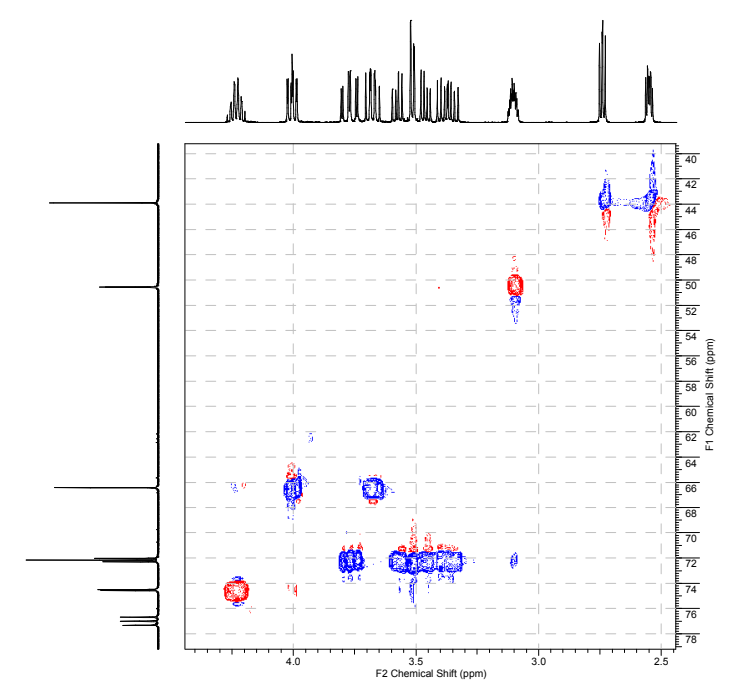

SF 4. 2D-HSQC-NMR in $\mathrm{CDCl}_{3}$ of $\mathbf{1}$. 


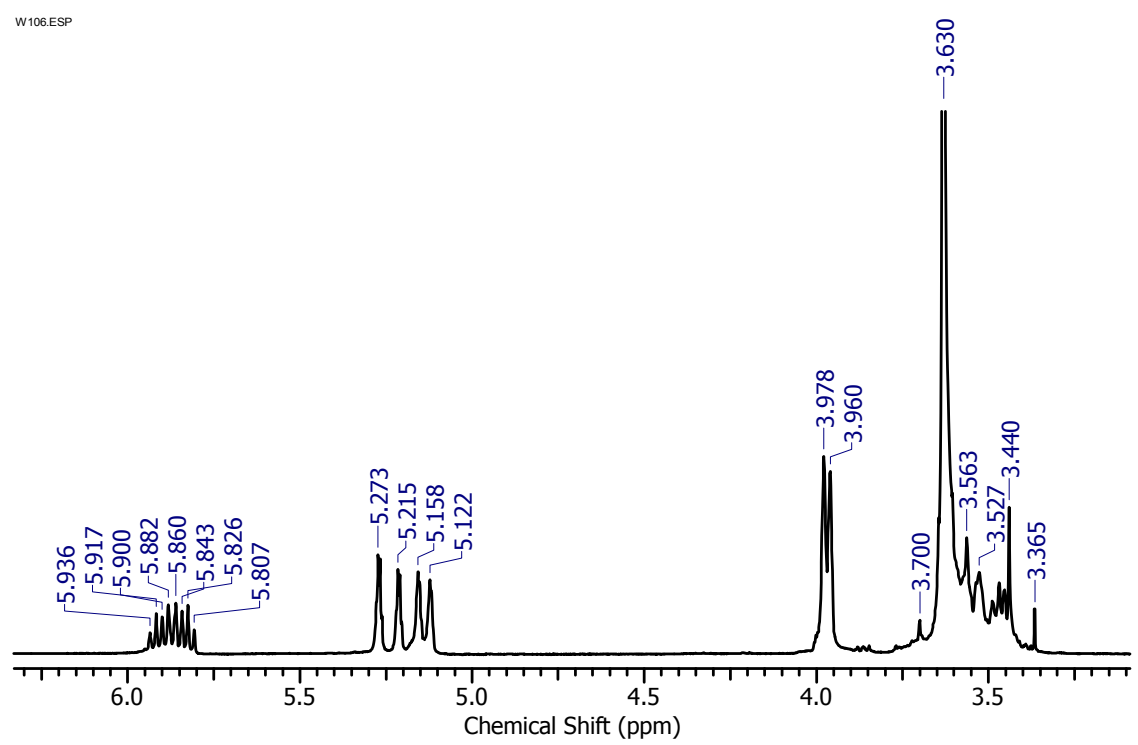

SF 5. ${ }^{1} \mathrm{H}-\mathrm{NMR}$ of a PEO-PAGE diblock copolymer in $\mathrm{CDCl}_{3}$.

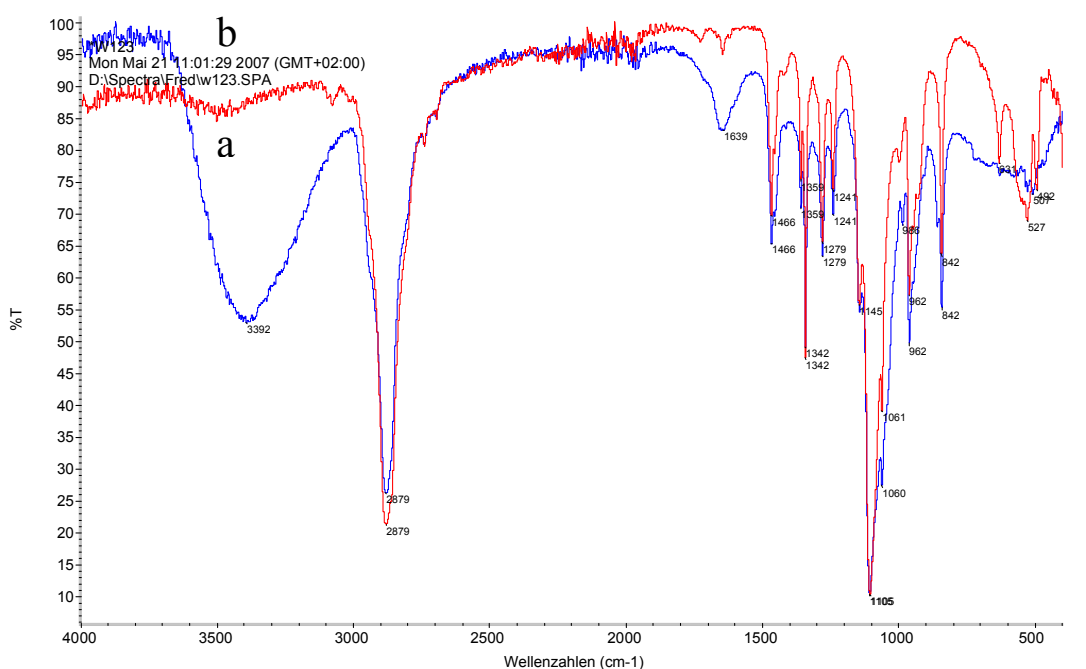

SF 6. IR-spectra of a PEO-PAGE (a) and PEO-PGG (b) diblock copoylmer. 